\section{Willis redevivus}

\section{Vernon Heywood}

The Plant-Book: A Portable Dictionary of the Higher Plants. By D.J. Mabberley. Cambridge University Press: 1987. Pp. 706. Flexi-cover $£ 20, \$ 34.50$.

J.C. WILLIS is one of the select company of botanists, like Hutchinson, Engler and Strasburger, who have become eponymous with a widely used publication. In the case of Willis it is his Dictionary of the Flowering Plants and Ferns, first published in two volumes under another title, over 80 years ago. Although Willis's greatest achievement was to come later during his 15 years as Director of the Royal Botanic Garden, Peradeniya, Sri Lanka, where his advancement of the Garden's scientific programme led to the establishment of the country's Department of Agriculture, it is for his Dictionary that he is best known.

The Dictionary, at least in its later editions, was a near-encyclopaedic vademecum of all the families and the important genera of flowering plants and ferns that the student was likely to come across, together with explanations of botanical terminology and a summary of infor mation about their scientific and economic value. As such it was one of the most useful botanical compendia ever published and was used by generations of students and professionals - "a familiar and cherished tool" as Sir George Taylor was later to describe it. The sixth and last edition was produced in 1931, and was reprinted five times. But in 1951, in view of the vast increase in the amount of information about plant systematics that had accumulated, it was decided to invite Mr H.K. Airy Shaw of Kew to produce a fresh edition which appeared in 1966.

The Airy Shaw revision differed from previous editions in that it confined the entries to strictly taxonomic matters and most of the information on economic uses, terminology, and common and vernacular names was omitted. Subsequently some of this information was partially updated and brought together in a companion volume A Dictionary of Useful and Everyday Plants (1974); that book was compiled by F.N. Howes and was seen through the press after his death by David Mabberley, the author of The Plant-Book.

So far, the history of this fascinating work. But how does the new book differ from the Airy Shaw edition of Willis's Dictionary? And will we need to use both (or all three)? I am happy to say that The Plant-Book is quite distinctive and will prove to be as indispensable a tool as its predecessors. It nicely complements the Dictionary, and although there is some considerable overlap Mabberley's work is usually to be preferred because it is more up-to-date and accurate.

The Plant-Book attempts to cover all currently accepted generic and family names and the commonly used English names of flowering plants and ferns. Accordingly most of the generic synonyms given in Airy Shaw/Willis are omitted. On the other hand, the generic entries give the family attribution, numbers of included species, distribution and, where appropriate, information on botanical, medicinal, agricultural, horticultural or other economic uses. An abbreviated reference is given to recent generic monographs. Useful comments are included on family relationships, especially where there is dissent from the viewpoint expressed in Cronquist's An Integrated System of Classification of Flowering Plants, the arrangement of which is otherwise followed by Mabberley for the angiosperm families. All this is contained within a volume of 700 pages, which also includes an acknowledgement of sources (some 150 books and about 500 periodicals).

\section{Radical thinking}

\section{John F. Ward}

The Chemical Basis of Radiation Biology. By C. von Sonntag. Taylor \& Francis: 1987. Pp.515. £49, \$98.

RESEARCH into the biological effects of ionizing radiation has commonly been concerned with the physics of energy deposition rather than the chemical processes involved. These processes involve the reactions of the free radicals, produced as a result of ionizations, with biomolecules. Recently there appears to be a greater acceptance of the contributions that chemistry can make - for instance, definition of the types of molecular damage caused within a cell by radiation (that is, the products of radical damage), and elucidation of the mechanisms of molecules known to modulate the action of radiation on cellular systems (by interference with radical processes).

The publication of this book is therefore timely. It is the first comprehensive account of the radiation chemistry of biological molecules. Beginning with a brief description of the techniques of radiation chemistry, it leads into a survey of the reactions of the free radicals which are produced by water radiolysis. The heart of the book, and its greatest value, lies in the detailed descriptions of the radiation chemistry of the biomolecules: nucleic acids, sulphur compounds, carbohydrates and proteins. Von Sonntag presents a detailed survey of these topics, drawing his material from an impressively broad literature base. His discussions are generally well argued and balanced, and,
The result, as far as I can judge on the basis of random sampling and checking, is remarkably good. There is a fair sprinkling of errors or misinterpretations, but this is inevitable and on the whole the book inspires the confidence which is most important in work of this kind.

The book is well printed and bound in a plastic case. It is indeed portable as the subtitle indicates and I predict that it will be commonly carried by students on their visits around botanic gardens as was Willis in my day. But more use of it will be made as a constant reference work by botanists, gardeners, agriculturists and others. Willis finished the preparation of his original book on the voyage out to Ceylon (Sri Lanka) - the island of Serendipity of the ancient mariners. What a marvellous serendipity this book is!

Vernon Heywood, a Professor in the Department of Botany, University of Reading, Whiteknights, Reading RG6 $2 A S$, UK, is currently on secondment to The International Union for Conservation of Nature and Natural Resources.

importantly, he points out where there are discrepancies among the findings of different groups. Where he considers that presentation of the full radiation chemical background to any topic is not within the purview of his book, he provides adequate references for further reading.

Some may quibble with the author's choice of emphasis or selection of references in particular sections, and with his language usage in some places (he mentions his apprehensions in these regards in the preface). In my view, however, the presentation and the language give the text von Sonntag's personal imprint and do not detract from its value. Moreover, the book has the usual advantages of a single-author work in its continuity and consistency from chapter to chapter.

In general, the contents appear to be error-free, despite the apparent mistake on the front cover: there, the upper structure is probably meant to be the glutathiyl radical, but it lacks two methylene groups (surely licence taken by the cover designer in attempting to attain balance).

Radiation chemists, particularly those wishing to move into radiation biology, will value this book for its comprehensive survey of the field and will use it as a reference source. Radiation biologists are more likely to use it as a text, though it will present a challenge to those without a good background in chemistry. In addition, the book should be of great use to those interested in oxygen radical damage who may be unaware of the wealth of information on the reactions of these radicals in the radiation literature.

John F. Ward is Chief of the Division of Radiation Biology, Department of Radiology, University of California at San Diego, La Jolla, California 92093, USA. 